\title{
ARTÍCULOS
}

\section{IMAGINARIOS DE LA CORRUPCIÓN POLÍTICA EN LAS REPRESENTACIONES CINEMATOGRAFICAS}

\section{IMAGINARIES OF POLITICAL CORRUPTION IN CINEMATOGRAPHIC REPRESENTATIONS}

\author{
José Arturo Corona Ruiz \\ joscorona@outlook.com \\ Universidad Autónoma de Chiapas
}

\section{RESUMEN}

La presente investigación busca el análisis de la corrupción en el cine mexicano contemporáneo y comercial, vista desde el análisis de contenido. Como es reconocido en el mundo, México es uno de los países con mayor número de prácticas corruptas, al menos en habla hispana ocupa la primera posición según el barómetro internacional que mide casos de corrupción en 183 países del mundo.

El tratamiento planteado para este proyecto será bajo la propuesta teórica de Krippendorff, bajo un sistema de categorías y reglas de codificación donde se analizará principalmente al filme mexicano La dictadura perfecta (2014).

Al poner sobre la mesa lo observado en el largometraje y categorizándolo, según el nivel de corrupción que Rubén Aroca propone, de esta forma comparar entre lo teórico y representado en la película. Al mismo tiempo el contexto político y social del país se relaciona con respecto a lo que se representa y como se representa en la cinematografía hecha en México. 


\section{INTRODUCCIÓN}

México el país más corrupto de América Latina, donde más de la mitad de los mexicanos $(51 \%)$ ha sobornado a las autoridades de acuerdo con el Barómetro Global de la Corrupción. Uno de los problemas más graves que aqueja al país, que afecta indudablemente a la fiabilidad que los ciudadanos tengan sobre su entorno político principalmente. A pesar de constituirse como uno de los principales problemas en todos los países de América Latina, la corrupción sigue siendo un fenómeno poco estudiado desde el punto de vista académico, y poco combatido desde el punto de vista político. (Ángel, 2016, p.312).

Las instituciones gubernamentales, las de acceso a servicios públicos son las que tienen mayor índice de corrupción según estadísticas nacionales e internacionales ${ }^{1}$. No obstante, en vivencias diarias es posible observar estos hechos como parte naturalizada de la contextualidad mexicana.

En el cine se han hecho filmes que relatan acontecimientos políticos y sociales, denominado cine de denuncia, donde puede adentrarse desde la mirada e intencionalidad del guionista y director, la forma en que plasma la temática a denunciar.

En este sentido se propone estudiar a la corrupción como eje temático en la representación en el cine y la realidad política-social (contextualismo mexicano) que sufre el país bajo las propuestas ya realizadas por otros teóricos latinoamericanos. El objetivo general es Rastrear las representaciones sobre la corrupción en el cine mexicano comercial contemporáneo, sus relaciones y diferencias con la información

\footnotetext{
${ }^{1}$ Las estadísticas otorgadas por la Auditoria Superior de la Federación (ASF) a nivel nacional e internacional por revistas especializadas y el Barómetro Global de la Corrupción
} 
| Cuatrimestral Facultad de Humanidades Campus VI

Reserva de Derechos al Uso Exclusivo No.: 04-2018-060814012200-203| ISSN: 2594-1755

Año II | Número 5 | Enero- Abril 2019

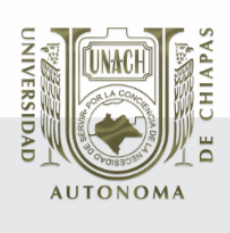

\section{ARTÍCULOS}

para la descripción objetiva, sistemática y cuantitativa del contenido manifiesto de la comunicación". Sin embargo, el alcancé que muestra Berelson se sale de los alcances que esta investigación tiene como objetivo, es así que el análisis se hará desde la propuesta Krippendorffiana.

Por el lado del análisis de contenido bajo las reglas de codificación considero a Andrés Solimano, Tanzi Vito y Felipe del Solar bajo los efectos multicausales de corrupción estatal, política, privada y no gubernamental. El siguiente esquema muestra cómo se concibe el análisis propuesto para esta investigación.

Las fases que se tienen consideradas para esta investigación son dos. La primera implica el análisis neto de la película separando y categorizando las imágenes que se muestren sobre prácticas de corrupción. La segunda fase corresponde a los años desde que se escribe la historia hasta el año de estreno exponer los principales hechos de corrupción en México.

Las técnicas de investigación a aplicar son la observación, entrevista, e investigación documental. Cumpliendo las fases señaladas la observación corresponde al filme que denotará el primer resultado de separar con la metodología de categorización de Aroca dentro del filme, y al mismo tiempo por el tipo que Solimano, Vito y del Solar establecen. Esto será bajo observación estructurada por medio de tablas que separen las categorías y tipos por los teóricos elegidos.

La investigación documental toma dos rumbos, entre lo relacionado a la película y lo relacionado a los hechos de corrupción según los años a establecer. Por un lado, la investigación documental de todo lo relacionado a la película desde que

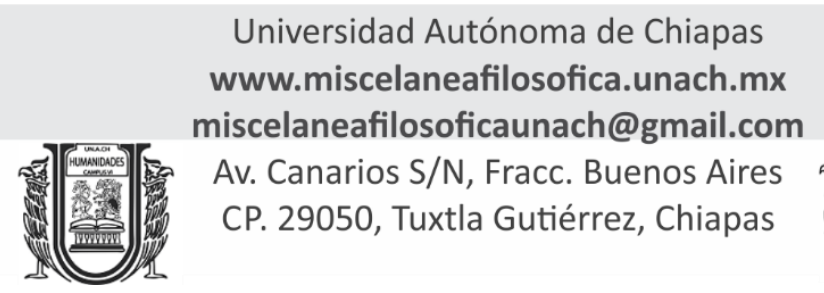


Desde la academia la corrupción ha sido poco estudiada y analizada sobre todo desde donde se plantea esta investigación. Empero los trabajos que se han hecho y que se han tenido el alcance de leer han mostrado un interés en categorizar y explicar este fenómeno-problema.

La asociación empleada de manera clásica es corrupción igual a política. Aristóteles concibió a la política como toda actividad orientada a la promoción del interés general o del bien común, a través de la redistribución de valores. Asimismo, pensó la política como un conflicto a priori que no hay que abolir, sino por el contrario mediatizar, o más bien, gobernar (Rossi \& Amadeo, 2002).

Es en las intersecciones del gobernar donde surgen problemas que no empatan en el funcionamiento idóneo de un sistema. Se puede afirmar que un gran conjunto de actividades se incluye bajo el concepto de corrupción; esta serie incluye el soborno, la malversación, el robo, el fraude, la extorsión, el abuso de la discreción y las contribuciones políticas indebidas (Ángel, 2012). En el sistema político a nivel mundial existe en diferente medida, número de situaciones y/o ejercicios considerados como corrupción.

Justamente a las actividades que se consideran parte de la corrupción teóricos han propuesto un diseño que explique a fondo el problema. Los enfoques clásicos de la corrupción como el desarrollado por Max Weber, se considera la corrupción como un fenómeno centrado en el Estado el cual está determinado por las intenciones subjetivas de las personas que quieren algún tipo de poder (Vargas-

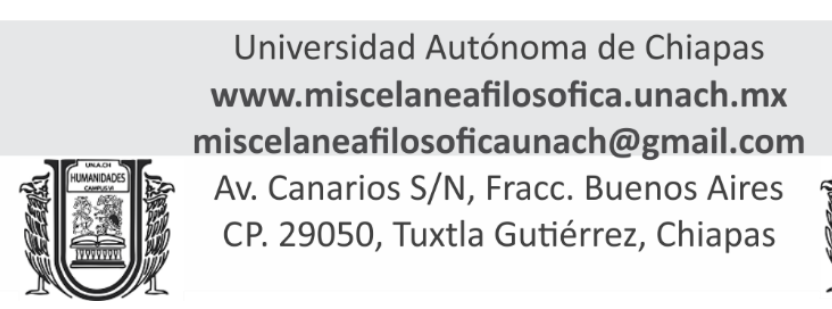


| Cuatrimestral Facultad de Humanidades Campus VI

Reserva de Derechos al Uso Exclusivo No.: 04-2018-060814012200-203| ISSN: 2594-1755

Año II | Número 5 | Enero- Abril 2019

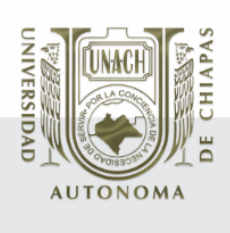

\section{ARTÍCULOS}

Hernández, 2009). Los enfoques contemporáneos son más amplios en el sentido de que incluyen la corrupción realizada por empresas privadas y por agentes no gubernamentales. Visto desde el lado meramente político en el ejercicio del Estado, aunque esto se fecunda más allá. No solamente el estado ejerce estas actividades corruptas, sino los reproductores activos son la sociedad, quienes con dolo por cualquier razón saben que hacen algo indebido y aun así continúan con las prácticas que Ángel, A. (2016) ha citado.

\section{Corrupción}

Las definiciones que se han hecho desde la academia, son amplias y variadas. Dan pie a la ampliación de cómo considerar lo que es y lo que no podría ser considerado como una práctica corrupta. Según Sautu (2004), el concepto de corrupción se define como el otorgamiento de beneficios materiales, tanto a funcionarios estatales como a políticos, a cambio de influir ilegalmente sus decisiones. Vargas (2009) muestra como algunas posturas han definido la corrupción como "el abuso de un cargo público para el beneficio privado" (p. 270). En algunos casos, la corrupción implica el pago de sobornos para financiar una decisión del Estado (Gamarra, 2006). En otros, la corrupción implica clientelismo, es decir, un sistema de privilegios en el que "los recursos son controlados por 'patrones' y se entregan a los clientes a cambio de deferencia y diversos tipos de apoyo" (Yusha'u, 2009, p. 162). La corrupción no sólo implica el pago de dinero, sino también algún tipo de intercambio de favores o beneficios (Solimano, Tanzi y del Solar, 2008). En la mayoría de los casos, implica un uso indebido del poder y refleja un fracaso de las instituciones políticas (Jain, 2001).

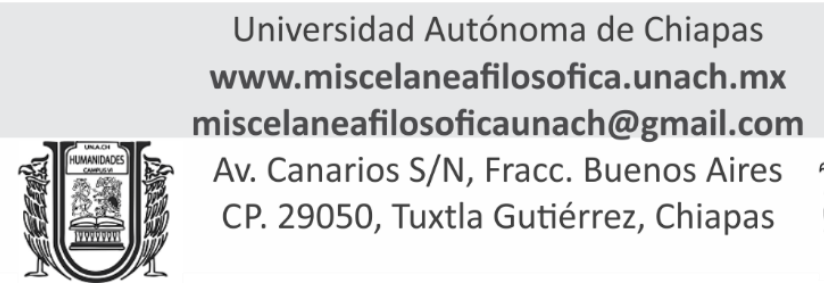


| Cuatrimestral Facultad de Humanidades Campus VI

Reserva de Derechos al Uso Exclusivo No.: 04-2018-060814012200-203| ISSN: 2594-1755

Año II | Número 5 | Enero- Abril 2019

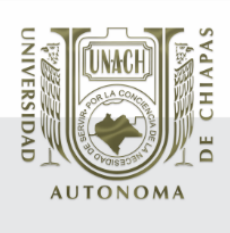

\section{ARTÍCULOS}

Las definiciones anteriores denotan el arraigo existente entre la corrupción y el ejercicio político gubernamental, el interés de estas definiciones subyace por los objetivos planteados en esta conexión entre lo que se observará en el largometraje y el contexto político de México.

De alguna manera en contraste con las definiciones anteriores. La corrupción podría concebirse como un fenómeno multicausal en el que intervienen factores económicos, culturales, políticos, históricos y sociales (Solimano, Tanzi y del Solar, 2008). Es justo aquí donde un grupo de teóricos no enlaza directamente al sistema del Estado, sino los múltiples factores de la causalidad de la corrupción más bien como problema social y no problema gubernamental. Interesa esta variación para comprender más allá de lo que sucede de forma social y política.

\section{Cine mexicano}

El cine mexicano ha destacado en los últimos años por producir una mayor cantidad de filmes, el último record 2017 donde se produjeron 176 películas. Desde la época de oro del cine mexicano no se veía tal cantidad de filmes, esto según el Instituto Mexicano de Cinematografía (IMCINE, 2018).

Aunque la cantidad de producto sea basta aún existen problemas de distribución y pocos géneros. No obstante, aquí el interés de la investigación nace por cómo se ha representado la corrupción en el cine de denuncia. Explica Cecilia García (2014),

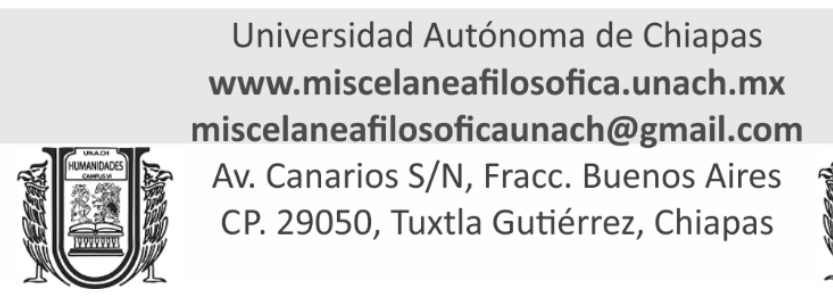


| Cuatrimestral Facultad de Humanidades Campus VI Reserva de Derechos al Uso Exclusivo No.: 04-2018-060814012200-203| ISSN: 2594-1755 Año II | Número 5 | Enero- Abril 2019

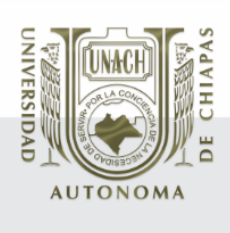

\section{ARTÍCULOS}

La corrupción, ya sea económica, política, social o vital siempre ha sido un material de primer orden para directores y guionistas por su potencial dramático. El cine negro y el cine de denuncia social han puesto con frecuencia el foco en determinadas decisiones del poder que han contribuido a la degeneración tanto de los sistemas políticos, tanto democráticos como dictatoriales, como de las personas que los sustentan y también que los sufren.

En un apartado sobre medios audiovisuales, los casos donde se estudia la corrupción han sido desde la televisión. Los pocos estudios sobre el tema -la mayoría de ellos obsoletos- atribuyen un papel ambiguo e incluso condenatorio a los medios de comunicación en su tarea de divulgar casos de corrupción.

\section{CONCLUSIONES}

La controversia alrededor del contenido cinematográfico ha suscitado al debate, aún más cuando la denuncia social se refleja por los problemas que padece la nación. Las formas en que estos problemas se representan y a quienes alucen o intentan representar en el caso del cine, es uno de los dilemas que a ciencia cierta no es posible conocer.

En la corrupción política los actores y actrices sociales de la vida política mexicana, parecen ser denuncia e inspiración al cine de denuncia y a sátiras políticas como el filme analizado. 
